\title{
Desenvolvimento e qualidade de plantas de Aechmea fasciata (Lindley) Baker com a utilização do cloreto de potássio ou do sulfato de potássio aplicados em três freqüiências por via foliar ${ }^{(1)}$
}

\author{
ELOIZA SANTANA SEIXAS VITÓRIA ${ }^{(2)}$ e IZABEL CRIST1NA LEITE ${ }^{(3)}$
}

\begin{abstract}
RESUMO
A freqüência como a adubação foliar é realizada em bromélias é muita variada não havendo uma regularidade, ocorrendo casos em que é feita de acordo com os aspectos da planta. O potássio está entre os nutrientes que contribuem para melhoria da qualidade de plantas, incluindo ornamentais. As fontes potássicas mais comumente utilizadas na agricultura são o cloreto e o sulfato de potássio, e na forma de sulfato de potássio para algumas ornamentais, produz plantas de melhor qualidade e maiores quantidades em comparação ao cloreto. Plantas de Aechmea fasciata foram submetidas a três frequiências de adubação potássica foliar utilizando-se duas fontes, cloreto de potássio e sulfato de potássio. Avaliaram-se as seguintes características: altura e diâmetro da planta, número de folhas, diâmetro do caule, massa seca de inflorescência, de escapo, de caule, de folhas, de raízes e total; diâmetro, comprimento e número de ramos da inflorescência, e a qualidade da planta. Observou-se que, de maneira geral, a adubação potássica foliar, independentemente da fonte e da frequiência, não proporcionou melhoria na produção e qualidade da planta, indicando que pode ser desnecessária para produção de Aechmea fasciata, o que resultaria em redução dos custos para sua produção.
\end{abstract}

Palavras-chave: adubação potássica, planta ornamental, bromélia.

\begin{abstract}
Development and quality of plants of Aechmea fasciata (Lindley) Baker with the use of potassium chloride or potassium sulphate in three frequencies applied on leaves
\end{abstract}

\begin{abstract}
The frequency as the foliar fertilization is carried through in bromeliad is much varied not having a regularity, occurring cases where the aspect of the plant is made in accordance with. The potassium is between the nutrients that contribute for improvement of the quality of plants, including ornamental. The potash sources more comumente used in agriculture are the potassium chloride and sulphate, and in the potassium sulphate form for some ornamental ones, it produces plants of better quality and greaters amounts in comparison to chloride.Plants of Aechmea fasciata had been submitted to the trees frequencies of leaf fertilization and two sources, potassium chloride and potassium sulfate. The follwing characteristics had been evaluated: plant height and diameter, number of leaves, diameter of stem, dry matter of inflorescence, floral scape, stem, roots and total dry matter; diameter, length and number of shoots of the inflorescence, and the plant quality. It was observed that, in general the foliar fertilization, independently of the source and frequence, did not increment prodution and plant quality, indicanting that application of potassium is not necessary for prodution of Aechmea fasciata, and this would result in decrease of the costs for its production.
\end{abstract}

Keys words: potash fertilization, ornamental plant, bromeliad.

\section{INTRODUÇÃO}

Afamília Bromeliaceae, conforme PAULA(2000) é composta por 2550 espécies conhecidas. Está dividida em três subfamílias: Pitcairnioideae, Tillandsioideae e Bromelioideae (WILLIAMS, 1990).

A adubação de bromélias é uma técnica utilizada pela maioria dos produtores, e a forma pela qual o nutriente é fornecido é variável.
Aechmea fasciata é uma planta epífita, e segundo KÄMPF (1994) tem grande capacidade de absorção de nutrientes pelas folhas.

A cultura de bromélias para fins comerciais, de acordo com ANDRADE e DEMATTÊ (2001), intensificouse no Brasil a partir da década de 90 . Por se tratar de uma cultura nova em nosso país, carece ainda de informações técnicas de cultivo em nossas condições climáticas, e que possam promover o incremento da produtividade e da qualidade. Várias são as dificuldades com que os produtores

\footnotetext{
(1) Parte da Tese de Doutorado da primeira autora, financiado pelo CNPq. Recebido em 29/11/2004 e Aprovado para publicação em 26/11/ 2007.

(2) eloizassvitoria@gmail.com

(3) Departamento de Biologia Aplicada à Agropecuária, Via de Acesso Prof. Paulo Donato Castellane, s/n, CEP- 14884-900, Jaboticabal, SP.
} 
têm se deparado. Entre elas, estão a utilização de substrato e adubação adequada, sendo fatores fundamentais para o cultivo.

O potássio $(\mathrm{K})$ é um metal alcalino que ocorre naturalmente na maioria das rochas. As plantas requerem K em quantidades comparativamente altas; por essa razão, ele é considerado, um dos três principais nutrientes vegetais. Apesar de não ser constituinte de qualquer estrutura das plantas ou de compostos, o potássio é essencial em quase todos os processos necessários para sustentar a vida da planta. Plantas deficientes em K não podem usar água e outros nutrientes de solos ou fertilizantes eficientemente, e são menos tolerantes a estresses ambientais, tais como: seca, excesso de água, vento e temperaturas baixas. A qualidade das plantas deficientes em potássio também é inferior. O potássio é conhecido como o nutriente da qualidade por causa de seus importantes efeitos em fatores como tamanho, forma, cor, sabor e resistência à armazenagem (MALAVOLTA,1980).

As fontes potássicas mais comumente utilizadas na agricultura são o cloreto de potássio e o sulfato de potássio. Segundo ZEHLER et al. (1986), o potássio na forma de sulfato de potássio para algumas ornamentais, produz plantas de melhor qualidade e maiores quantidades em comparação ao cloreto de potássio.

A importância do potássio para bromélias tem sido relatada por muitos pesquisadores (POOLE e CONOVER, 1976; PLEVER, 1996; JIMENEZ MEJIAS e CABALLERO RUANO, 1990; KÄMPF, 1994), os quais sugerem que o nutriente, em proporções adequadas, poderá proporcionar melhoria na qualidade da planta.

Em estudo realizado por ANDRADE e DEMATTÊ (1999) sobre produção e comercialização de bromélias nas regiões Sul e Sudeste do Brasil, verificou-se que a atividade não tem sido orientada com base em informação científica. A adubação é feita de forma muito variada; a freqüência da adubação foliar chamou muito a atenção, porque não havia uma regularidade, ocorrendo casos em que a frequiência era feita de acordo com os aspecto da planta, entretanto a maioria realizava semanalmente, seguida pela quinzenal. Há grande preocupação entre as proporções de N, P e K, e consenso sobre a importância do uso do potássio. Os autores consideram que essas observações sugerem a necessidade de desenvolvimento de uma linha de investigação científica que obtenha dados que orientem, com mais recursos, a atividade dos produtores e que testes realizados em situações controladas, bem analisados, podem fornecer dados que levem a uma economia na produção tanto de recursos como de tempo. Assim sendo, a experiência prática, o conhecimento próprio de cada produtor e a troca de informações entre pessoas envolvidas com a Família Bromeliaceae, tanto cultivadores como colecionadores, são as principais fontes de informações para a tomada de decisões quanto aos recursos técnicos a serem utilizados nas áreas produtoras.

Considerando-se os fatores mencionados, este trabalho teve por objetivo estudar o efeito de fontes de potássio e frequiências de adubação foliar na produção de Aechmea fasciata.

\section{MATERIALEMÉTODOS}

O experimento foi instalado e conduzido no Setor de Mudas da Empresa Mec Prec, localizada em Telêmaco Borba (PR), cujas coordenadas são as seguintes: latitude sul de $24^{\circ} 32^{\prime}$ e longitude de $50^{\circ} 62^{\prime}$, altitude 844 metros. O clima, pela classificação de Koeppen, é do tipo Cfa, com precipitação anual de $1400 \mathrm{~mm}$, a temperatura média durante o período de condução do trabalho foi de $22,12^{\circ} \mathrm{C}$. A casa de vegetação tinha $5 \mathrm{~m}$ de largura e $22 \mathrm{~m}$ de comprimento era coberta com filme de polietileno aditivado e, conforme é utilizado pelos produtores de bromélias para fins comerciais, o sombreamento utilizado na casa-devegetação era feito com tela de sombreamento de $70 \%$. Os vasos foram dispostos na estufa em três bancadas de madeira, posicionadas no sentido longitudinal, Norte-Sul, com 1,60 m de largura, $21 \mathrm{~m}$ de comprimento e 0,70 de altura.

Mudas de Aechmea fasciata (Lindey) Baker micropropagadas foram obtidas da Empresa Rolf Bromélias, com 110 dias de idade, com número médio de 7,83 folhas por planta, foram cultivadas por 390 dias até o florescimento, quando estavam aptas para comercialização.

O substrato utilizado, necessário para o enchimento de 84 vasos, era composto de $45 \%$ de casca de pinus, $45 \%$ de fibra de coco e $10 \%$ de húmus de minhoca, com base no volume; dessa maneira preparou-se um total de 37,8 litros para primeira fase e 105 litros para segunda; essa foi a mistura sem xaxim que apresentou os melhores resultados em trabalho realizado por D'ANDREA(1997). A casca de pinus foi fornecida pela empresa Mec Prec Ltda, a fibra de coco da empresa Amafibra, e o húmus de minhoca, pela empresa Santa Rita Ltda.

Os diferentes componentes de cada substrato foram colocados em um recipiente (balde), nas proporções indicadas, misturados e depois acondicionados em vasos plásticos devidamente identificados.

Inicialmente as plantas foram cultivadas em vasos de plástico, com capacidade de 0,45 L, onde permaneceram por seis meses. Posteriormente, foram transferidas para vasos com capacidade de 1,25 L, onde permaneceram até o final do experimento. Os vasos foram preenchidos no fundo com pedras britadas, para facilitar a drenagem, com base nas informações de KANASHIRO (1999)

Para adubação radicular, durante o cultivo em vaso, utilizou-se o adubo de liberação lenta do tipo "Osmocote" (NPK), na formulação 15-10-10, contendo 3,5\% de $\mathrm{Ca}, ; 1,5 \%$ de $\mathrm{Mg} ; 3 \%$ de $\mathrm{S} ; 0,02 \%$ de $\mathrm{B} ; 0,05 \%$ de $\mathrm{Cu}$; $0,05 \%$ de Fé; $0,1 \%$ de $\mathrm{Mn} ; 0,004 \%$ de Mo e $0,05 \%$ de Zn; utilizando-se a quantidade de seis gramas por litro de substrato, sendo esta realizada no plantio e seis meses depois, conforme recomendação do fabricante, em todas as plantas.

A irrigação foi realizada duas vezes por semana e, durante o inverno, foi semanal. $\mathrm{O}$ pH da água era de 6,5 e condutividade elétrica de $0,1 \mathrm{mSc} / \mathrm{cm}^{3}$. 
Seguindo as instruções de Lele-Grau e Messeguer-Peypoch (1980), citados por KANASHIRO (1999), a indução floral foi realizada cinco meses após o transplante para o vaso de plástico número 15 , em outubro de 2003, com ethephon (ácido 2-cloroetilfosfônico), aplicando-se $125 \mathrm{~mL}$ de uma solução com $720 \mathrm{mgL}^{-1}$ do princípio ativo. Nesse período as plantas apresentavam uma média 12,4 folhas. Antes da aplicação, a água contida nas cisternas foi eliminada, virando-se a planta, aplicandose em seguida, no centro da roseta, a solução indutora.

As fontes potássicas foram cloreto de potássio e sulfato de potássio, aplicados em três frequiências de adubação, desde o plantio até a fase de florescimento: semanal, quinzenal e mensal, na concentração de $0,1 \%$ recomendada por KÄMPF (1994) da fórmula 7-17-35 utilizada por KANASHIRO (1999), que corresponde a 0,583 $\mathrm{g} / \mathrm{L}$ de $\mathrm{KCI}$ e $0,7 \mathrm{~g} / \mathrm{L}$ de $\mathrm{K}_{2} \mathrm{SO}_{4}$. O experimento foi conduzido em delineamento inteiramente casualizado, em esquema fatorial $(3 \times 2+1)$, em que os fatores foram frequiência, fontes de $\mathrm{K}$ e uma testemunha, com quatro repetições contendo uma planta por vaso, sendo a unidade experimental constituída por três plantas, totalizando 84 plantas.

Foram avaliadas as seguintes características: número de folhas, altura da planta, diâmetro da planta, comprimento da inflorescência, diâmetro da inflorescência, número de ramos, massa seca de folhas, massa seca da inflorescência, massa seca do escapo floral, massa seca de raiz e massa seca de caule e massa seca total. A qualidade comercial foi avaliada através do critério de notas, variando de um a três, de acordo com KANASHIRO (1999):

- Nota 1: plantas com ótima qualidade comercial, tanto para folhas como inflorescência; apresentando coloração e vigor intenso.

- Nota 2: plantas com boa qualidade comercial, tanto para folhas como inflorescência, mas com pouco vigor.

- Nota 3: plantas com defeito, sem condições de comercialização, com folhas e inflorescência pequenas e amareladas.

Os dados coletados foram submetidos à análise de variância, em esquema fatorial, os dados de qualidade transformados em arc.sen. (x/100) $)^{1 / 2} \mathrm{e}$ a comparação entre médias foram feitos com aplicação do teste de Tukey, em nível de 5\% de probabilidade de erro (PIMENTEL GOMES, 1978).

\section{RESULTADOS E DISCUSSÃO}

As propriedades químicas do substrato utilizado encontram-se na tabela 1.
Realizou-se análise foliar, e obteve-se resultados significativos apenas para fonte cloreto de potássio em apenas três nutrientes, em que Cálcio, Manganês e Ferro apresentaram os maiores valores (dados não apresentados).

A tabela 2 informa as características avaliadas da parte vegetativa, verificou-se nos tratamentos realizados que as fontes potássicas utilizadas proporcionaram diferenças significativas somente para número de folhas, sendo que o sulfato de potássio proporcionou os maiores valores.

Para freqüência de adubação, a aplicação mensal resultou em maiores valores de altura da planta (sem diferir da semanal), número de folhas; para o diâmetro da planta, a aplicação semanal não diferiu significativamente da quinzenal, apenas da mensal; o diâmetro do caule diferiu significativamente nas frequiências comparadas. Para as características da parte vegetativa (tabela 2), a testemunha apresentou maiores valores que os tratamentos, exceto para o diâmetro da planta, ou seja, o potássio pouco influenciou. Também FREITAS (1996) verificou em seu trabalho com lírio amarelo, que não houve diferenças significativas nas características de crescimento (altura e número de folha) para intervalos de aplicação de adubo potássico.

Para medidas da inflorescência, (tabela 3), verifica-se que as fontes e as freqüências de aplicação testadas resultaram em efeitos significativos somente para comprimento, e que o cloreto de potássio e a adubação semanal - seguida pela quinzenal - apresentaram inflorescências de maiores comprimentos. $\mathrm{O}$ diâmetro e número de ramos da inflorescência, não sofreram efeito de fonte e frequiência. Ainda, na tabela 3, observa-se que a testemunha apresentou inflorescência de menor diâmetro e maior comprimento.

$\mathrm{Na}$ tabela 4 constam os dados de massa seca de inflorescência, escapo, caule, folhas raízes e total. Para os tratamentos realizados, observou-se efeito significativo somente para frequiência de adubação na massa seca do caule, sendo que a frequiência quinzenal apresentou maiores valores que a semanal. A testemunha, em todas as características avaliadas, obteve os maiores valores de massa seca. FREITAS (1996) não encontrou diferença significativa no parcelamento do adubo potássico em relação à matéria seca da parte aérea de lírio amarelo.Tal resultado em parte, pode ser explicado conforme MALAVOLTA (1980) que o íon potássio é o cátion mais abundante no tecido vegetal, pode ocorrer o fenômeno chamado "adubação de luxo"; portanto, nesse caso, um aumento no fornecimento do elemento não resultaria em aumento da produção de matéria seca.

Tabela 1. Propriedades químicas do substrato utilizado.

Table 1. Chemical properties of substrate.

\begin{tabular}{|c|c|c|c|c|c|c|c|c|}
\hline $\mathrm{pH}$ & $\begin{array}{l}\text { Matéria orgânica } \\
\text { Organic matter }\end{array}$ & $\mathrm{P}$ & K & $\mathrm{Ca}$ & $\mathrm{Mg}$ & SB & $\mathrm{T}$ & V \\
\hline$\overline{\mathrm{em} \mathrm{CaCl}}{ }_{2}$ & $\mathrm{~g} / \mathrm{dm}^{3}$ & $\mathrm{mg} / \mathrm{dm}^{3}$ & & & $\mathrm{mmol} / \mathrm{dm}^{3}$ & & & $\%$ \\
\hline 5,0 & 195 & 220 & 16,5 & 73 & 50 & 139,5 & 181,17 & 77 \\
\hline
\end{tabular}


Verificou-se neste experimento, de maneira geral, que a testemunha, sem adubação foliar, apresentou valores superiores para quase todas as características avaliadas, com exceção somente para o diâmetro da inflorescência. Isso, em parte, pode ser explicado pelo fato de que, possivelmente, o adubo utilizado no substrato (tabela 1), tenha fornecido a quantidade de potássio suficiente para que a planta pudesse desenvolver-se normalmente, e que qualquer acréscimo no fornecimento do nutriente, foi prejudicial ao desenvolvimento da planta. Verificou-se que a adubação foliar foi desnecessária, indicando que a planta conseguiu desenvolver-se normalmente. Em casos semelhantes, a adubação foliar poderia deixar de ser feita, resultando em maior economia de produto e mão-de-obra. De acordo com MALAVOLTA (1980), uma pequena porção no tecido já é o suficiente para ativar suas enzimas e desenvolver-se.

Para qualidade comercial, na tabela 5, observouse que houve efeito significativo para fonte, em que o cloreto de potássio produziu plantas de melhor qualidade comercial tanto para folhas e coloração. As diferentes freqüências não influenciaram nessa característica e a testemunha não diferiu dos tratamentos aplicados. POOLE e CONVER (1976), em experimento com Aechmea fasciata, verificaram que à medida que houve aumento da dose de potássio (60, 120 e $180 \mathrm{mg} / \mathrm{vaso}$ ) houve melhoria na qualidade, mas não na coloração. Segundo PEREIRA et al. (1994), em outras culturas observa-se relação do potássio com a coloração, embora essa relação não seja bem definida. Verificou-se que a cor vermelha aumentou com o acréscimo de mais de potássio em plantas deficientes quando os valores foliares não eram superiores a $0,5 \%$, dessa maneira como já foi fornecido potássio via adubação no substrato, a cor das inflorescências não foi melhorada.

\section{CONCLUSÃO}

Nas condições do presente trabalho, observouse que de maneira geral, a adubação potássica foliar, independentemente da fonte e freqüência, não proporcionou melhoria na produção e qualidade de plantas de Aechmea fasciata.

Tabela 2. Valores médios de medidas da parte vegetativa de Aechmea fasciata (Lindley) Baker submetida a duas fontes potássicas em três freqüências de adubação potássica foliar.

Table 2. Average values of measures of part of vegetative Aechmea fasciata (Lindley) Baker subjected to two potassium sources in three frequencies of foliar fertilization.

\begin{tabular}{|c|c|c|c|c|}
\hline $\begin{array}{c}\text { Tratamentos } \\
\text { Treatments }\end{array}$ & $\begin{array}{l}\text { Altura da planta } \\
\text { Height of plant } \\
(\mathrm{cm})\end{array}$ & $\begin{array}{l}\text { Diâmetro da planta } \\
\text { Diameter of plant } \\
(\mathrm{cm})\end{array}$ & $\begin{array}{l}\text { Número de Folhas } \\
\text { Number of leaves }\end{array}$ & $\begin{array}{l}\text { Diâmetro do caule } \\
\text { Diameter of stem } \\
(\mathrm{mm})\end{array}$ \\
\hline Fonte/ Source (Fo) & & & & \\
\hline $\begin{array}{l}\text { Cloreto de potássio } \\
\text { Potassium chloride }\end{array}$ & $21,58 \mathrm{a}$ & $43,24 \mathrm{a}$ & $13,24 \mathrm{~b}$ & $24,00 \mathrm{a}$ \\
\hline $\begin{array}{l}\text { Sulfato de potássio } \\
\text { Potassium Sulfate }\end{array}$ & $22,61 \mathrm{a}$ & $43,55 \mathrm{a}$ & $14,33 \mathrm{a}$ & 25,19 a \\
\hline $\begin{array}{l}\text { Teste F } \\
\text { F Test }\end{array}$ & $1,43 \mathrm{~ns}$ & $0,05 \mathrm{~ns}$ & $8,45 * *$ & $2,43 \mathrm{~ns}$ \\
\hline DMS (5\%) & 1,78 & 2,81 & 0,77 & 1,59 \\
\hline $\begin{array}{l}\text { Freqüiência } \\
\text { Frequencies (Fr) }\end{array}$ & & & & \\
\hline $\begin{array}{l}\text { Semanal } \\
\text { Weekly }\end{array}$ & $22,04 \mathrm{ab}$ & $46,24 \mathrm{a}$ & $13,66 \mathrm{~b}$ & $24,91 \mathrm{a}$ \\
\hline $\begin{array}{l}\text { Quinzenal } \\
\text { Fortnightly }\end{array}$ & $20,71 \mathrm{~b}$ & $43,99 \mathrm{ab}$ & $12,87 \mathrm{~b}$ & $23,74 \mathrm{a}$ \\
\hline $\begin{array}{l}\text { Mensal } \\
\text { Monthly }\end{array}$ & $23,54 \mathrm{a}$ & $39,95 \mathrm{~b}$ & $14,83 \mathrm{a}$ & $25,12 \mathrm{a}$ \\
\hline $\begin{array}{l}\text { Teste } \mathrm{F} \\
F \text { Test } \\
\end{array}$ & $3,63 * *$ & $7,41 * *$ & $9,26^{* *}$ & $1,25 \mathrm{~ns}$ \\
\hline DMS $(5 \%)$ & 2,65 & 4,17 & 1,15 & 2,36 \\
\hline $\begin{array}{l}\text { Teste F } \\
\text { F Test (Fo x Fr) }\end{array}$ & $1,81 \mathrm{~ns}$ & $0,80 \mathrm{~ns}$ & $2,32 \mathrm{~ns}$ & $1,66 \mathrm{~ns}$ \\
\hline $\begin{array}{l}\text { Fatorial } \\
\text { Factorial (Fat) }\end{array}$ & $22,09 \mathrm{~b}$ & $43,27 \mathrm{a}$ & $11,31 b$ & $24,59 \mathrm{~b}$ \\
\hline $\begin{array}{l}\text { Testemunha } \\
\text { Control }(\mathrm{T})\end{array}$ & $25,00 \mathrm{a}$ & 44,58 a & $15,66 \mathrm{a}$ & 30,08 a \\
\hline $\begin{array}{l}\text { Teste } \mathrm{F} \\
\mathrm{F} \text { Test }(\text { Fat x T) }\end{array}$ & $6,53 * *$ & $0,43 \mathrm{~ns}$ & $14,45 * *$ & 29,37 \\
\hline $\mathrm{CV}(\%)$ & 9,35 & 7,60 & 6,50 & 7,39 \\
\hline
\end{tabular}




\section{REFERÊNCIAS}

ANDRADE, F.S.A.; DEMATTÊ, M.E.S.P. Estudo sobre produção e comercialização de bromélias nas regiões Sul e Sudeste do Brasil. Revista Brasileira de Horticultura Ornamental, Campinas, v. 5, n.2, p. 97-110, 2001.

D'ÁNDREA, J.C. Substratos e fertilizantes para cultivo de Aechmea fasciata Bak. (Bromeliaceae). Jaboticabal, 1997. 49 f. Trabalho (Graduação em Agronomia) - Faculdade de Ciências Agrárias e Veterinárias, Universidade Estadual Paulista "Júlio de Mesquita Filho", Jaboticabal, 1997.

FREITAS, S. A.C. Efeitos de adubação fosfatada no plantio e da aplicação em cobertura de salitre duplo potássico na cultura do lírio amarelo (Hemerocallis lilioasphodelus Linnaeus) 76 f. Dissertação (Mestrado em Agronomia )Universidade Federal de Lavras, Lavras. 1996.

JIMENEZ MEJIAS, R.M.; CABALLERO RUANO, M.R. El cultivo industrial de plantas em maceta. Réus: Ediciones de Horticultura, 1990. $664 \mathrm{p}$
KÄMPF, A.N. Adubação foliar em Aechmea fasciata (Lindley) Baker. Bromélia, Rio de Janeiro, v.1, n.4, p.16-20, 1994.

KANASHIRO, S. Efeitos de diferentes substratos na produção da espécie Aechmea fasciata (Lindley) Baker em vasos. 1999. 79 f. Dissertação (Mestrado em Fitotecnia). - Escola Superior de Agricultura Luiz de Queiroz, Universidade de São Paulo, Piracicaba.

MALAVOLTA, E. Elementos da nutrição mineral de plantas. Piracicaba: Ceres, 1980.251 p.

PAULA, C.C. Cultivo de bromélias. Viçosa: Aprenda Fácil, 2000. 139p.

PEREIRA, F. M.;COUTINHO, E. L. M.; OLIVEIRA, F. Importância da adubação na qualidade das frutas de clima temperado. In: SÁ, M. E.; BUZZETI (Coord.) Importância da adubação na qualidade dos produtos agrícolas. São Paulo: Ícone, p. 161-175. 1994.

PIMENTEL GOMES, F. Curso de estatística

experimental. 5.ed. Piracicaba: Esalq/Usp, 1978.430 p.

Tabela 3. Valores médios diâmetro, comprimento e número de ramos da inflorescência de Aechmea fasciata (Lindley) Baker. submetida a duas fontes potássicas em três frequiências de adubação potássica foliar.

Table 3. Average values of measures of diameter, length and numbers inflorescence of Aechmea fasciata (Lindley) Baker subjected to two potassium sources of in three frequencies of foliar fertilization.

\begin{tabular}{|c|c|c|c|}
\hline \multirow[b]{2}{*}{$\begin{array}{l}\text { Tratamentos } \\
\text { Treatments }\end{array}$} & \multicolumn{3}{|c|}{$\begin{array}{l}\text { Características da inflorescência } \\
\text { Inflorescence characteristics }\end{array}$} \\
\hline & $\begin{array}{c}\text { Diâmetro } \\
\text { Diameter } \\
(\mathrm{cm}) \\
\end{array}$ & $\begin{array}{c}\begin{array}{c}\text { Comprimento } \\
\text { Lenght }\end{array} \\
(\mathrm{cm}) \\
\end{array}$ & $\begin{array}{l}\text { Número de ramos } \\
\text { Number shoots }\end{array}$ \\
\hline Source $(\mathrm{Fo})$ & & & \\
\hline $\begin{array}{l}\text { Cloreto de potássio } \\
\text { Potassium chloride }\end{array}$ & 10,69 a & 8,97 a & $7,11 \mathrm{a}$ \\
\hline $\begin{array}{l}\text { Sulfato de potássio } \\
\text { Potassium sulfate }\end{array}$ & $10,24 \mathrm{a}$ & $8,24 \mathrm{~b}$ & 6,77 a \\
\hline $\begin{array}{l}\text { Teste F } \\
\text { F Test }\end{array}$ & $1,41 \mathrm{~ns}$ & $11,11 *$ & $0,39 \mathrm{~ns}$ \\
\hline DMS $(5 \%)$ & 0,81 & 0,46 & 1,14 \\
\hline $\begin{array}{l}\text { Frequiência } \\
\text { Frequencies (Fr) }\end{array}$ & & & \\
\hline $\begin{array}{l}\text { Semanal } \\
\text { Weekly }\end{array}$ & 10,77 a & $9,09 \mathrm{a}$ & $7,16 \mathrm{a}$ \\
\hline $\begin{array}{l}\text { Quinzenal } \\
\text { Fortnightly }\end{array}$ & $10,72 \mathrm{a}$ & $8,43 \mathrm{ab}$ & $7,50 \mathrm{a}$ \\
\hline $\begin{array}{l}\text { Mensal } \\
\text { Monthly }\end{array}$ & $9,09 \mathrm{a}$ & $8,30 \mathrm{~b}$ & $6,16 \mathrm{a}$ \\
\hline $\begin{array}{l}\text { Teste } \mathrm{F} \\
\text { F Test } \\
\end{array}$ & $2,25 \mathrm{~ns}$ & $4,99 * *$ & $2,25 \mathrm{~ns}$ \\
\hline DMS (5\%) & 1,21 & 0,69 & 1,17 \\
\hline $\begin{array}{l}\text { Teste } \mathrm{F} \\
\text { F Test (Fo x Fr) } \\
\end{array}$ & $0,71 \mathrm{~ns}$ & $0,17 \mathrm{~ns}$ & $0,52 \mathrm{~ns}$ \\
\hline $\begin{array}{l}\text { Fatorial } \\
\text { Factorial (Fat) }\end{array}$ & $10,48 \mathrm{a}$ & $8,60 \mathrm{~b}$ & $6,9 \mathrm{a}$ \\
\hline $\begin{array}{l}\text { Testemunha } \\
\text { Control }(\mathrm{T}) \\
\end{array}$ & $9,03 \mathrm{~b}$ & 11,70 a & $8,3 \mathrm{a}$ \\
\hline $\begin{array}{l}\text { Teste } \mathrm{F} \\
\mathrm{F} \text { Test }(\text { Fat } \times \mathrm{T})\end{array}$ & $8,02 * *$ & $114,43^{* *}$ & $3,86 \mathrm{~ns}$ \\
\hline $\mathrm{CV}(\%)$ & 7,82 & 5,12 & 15,87 \\
\hline
\end{tabular}

\footnotetext{
** Médias seguidas por letras distintas diferem entre si pelo Teste de Tukey em nível de $1 \%$ de probabilidade.

** Averages followed by differents letter differ themselves by the Tukey test at $1 \%$.

* Médias seguidas por letras distintas diferem entre si pelo Teste de Tukey em nível de $5 \%$ de probabilidade.

* Averages followed by different letter differ themselves by the Tukey test at $5 \%$.

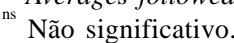

${ }^{n s}$ Not signficant.
} 
PLEVER, $H$. The fertilizer revolution. Journal of the Bromeliad Society, Orlando, v. 46, n.6, p. 252-260, 1996.

POOLE, R.T.; CONOVER, C.A. Nitrogen, phosphorus, and potassium fertilization of the bromeliad, Aechmea fasciata, Baker. Hortscience, Alexandria, v.11, n.6, p.585586, 1976.
WILLIANS, B.E. Growing bromeliads. 2.ed. Kenthurst: Kangaroo, 1990, 112 p.

ZEHLER, R.; KREIPE, H.; GETHING P.A. Cloreto de potássio e sulfato de potássio: sua influência na produção e na qualidade das plantas cultivadas.

Campinas: Fundação Cargill, 1986.111p

Tabela 4. Valores médios massa seca de inflorescência, escapo, caule, folhas, raízes e total de Aechmea fasciata (Lindley) Baker submetida a duas fontes potássicas em três frequiências de adubação potássica foliar.

Table 4. Average values of dry matter of inflorescence, floral escape, stem, leaves, roots and total of Aechmea fasciata (Lindley) Baker subjected to two potash sources in three frequencies of foliar fertilization

\begin{tabular}{|c|c|c|c|c|c|c|}
\hline \multirow{2}{*}{$\begin{array}{l}\text { Tratamentos } \\
\text { Treatments }\end{array}$} & \multicolumn{6}{|c|}{ Massa seca / Dry matter (g) } \\
\hline & $\begin{array}{l}\text { Inflorescência } \\
\text { Inflorescence }\end{array}$ & $\begin{array}{l}\text { Escapo } \\
\text { Escape }\end{array}$ & $\begin{array}{l}\text { Caule } \\
\text { Caule }\end{array}$ & $\begin{array}{l}\text { Folhas } \\
\text { Leaves }\end{array}$ & $\begin{array}{l}\text { Raiz } \\
\text { Roots }\end{array}$ & Total \\
\hline \multicolumn{7}{|l|}{ Fonte } \\
\hline \multicolumn{7}{|l|}{ Source $(\mathrm{Fo})$} \\
\hline $\begin{array}{l}\text { Cloreto de potássio } \\
\text { Potassium chloride }\end{array}$ & 7,45 a & $3,75 \mathrm{a}$ & $5,77 \mathrm{a}$ & 43,15 a & $3,16 \mathrm{a}$ & 63,25 a \\
\hline $\begin{array}{l}\text { Sulfato de potássio } \\
\text { Potassium sulfate }\end{array}$ & 6,96 a & $3,24 \mathrm{a}$ & $5,74 \mathrm{a}$ & 39,48 a & $3,95 \mathrm{a}$ & 59,08 a \\
\hline $\begin{array}{l}\text { Teste F } \\
\text { F Test }\end{array}$ & $0,27 \mathrm{~ns}$ & $0,38 \mathrm{~ns}$ & $0,01 \mathrm{~ns}$ & $0,45 \mathrm{~ns}$ & $1,53 \mathrm{~ns}$ & $0,34 \mathrm{~ns}$ \\
\hline DMS $(5 \%)$ & 2.02 & 1.77 & 0,86 & 11,73 & 1,36 & 15.30 \\
\hline \multicolumn{7}{|l|}{$\begin{array}{l}\text { Frequiência } \\
\text { Frequencies (Fr) }\end{array}$} \\
\hline $\begin{array}{l}\text { Semanal } \\
\text { Weekly }\end{array}$ & $7,66 \mathrm{a}$ & $3,45 \mathrm{a}$ & $4,96 \mathrm{~b}$ & 44,21 a & $4,21 \mathrm{a}$ & $64,51 \mathrm{a}$ \\
\hline $\begin{array}{l}\text { Quinzenal } \\
\text { Fortnightly }\end{array}$ & $6,98 \mathrm{a}$ & $4,00 \mathrm{a}$ & 6,40 a & 48,21 a & $3,41 \mathrm{a}$ & $69,01 \mathrm{a}$ \\
\hline $\begin{array}{l}\text { Mensal } \\
\text { Monthly }\end{array}$ & 6,98 a & $3,05 \mathrm{a}$ & $5,91 \mathrm{ab}$ & $31,53 \mathrm{a}$ & $3,05 \mathrm{a}$ & 49,98 a \\
\hline $\begin{array}{l}\text { Teste F } \\
\text { F Test }\end{array}$ & $0,23 \mathrm{~ns}$ & $0,44 \mathrm{~ns}$ & $4,39 *$ & $3,37 \mathrm{~ns}$ & $1,16 \mathrm{~ns}$ & $2,59 \mathrm{~ns}$ \\
\hline DMS (5\%) & 3.02 & 2.66 & 1.28 & 17.54 & 2.04 & 22.88 \\
\hline $\begin{array}{l}\text { Teste } \mathrm{F} \\
\mathrm{F} \text { Test }(\mathrm{Fo} \times \mathrm{Fr})\end{array}$ & $0,23 \mathrm{~ns}$ & $0,29 \mathrm{~ns}$ & $1,82 \mathrm{~ns}$ & $0,85 \mathrm{~ns}$ & $0,44 \mathrm{~ns}$ & $0,73 \mathrm{~ns}$ \\
\hline $\begin{array}{l}\text { Fatorial } \\
\text { Factorial (Fat) }\end{array}$ & $7,21 \mathrm{a}$ & $3,5 \mathrm{~b}$ & $5,75 \mathrm{~b}$ & $41,32 \mathrm{~b}$ & $3,56 \mathrm{~b}$ & $61,17 \mathrm{~b}$ \\
\hline $\begin{array}{l}\text { Testemunha } \\
\text { Control }(\mathrm{T})\end{array}$ & 8,06 a & $7,7 \mathrm{a}$ & $7,03 \mathrm{a}$ & 58,46 a & $7,20 \mathrm{a}$ & 85,03 a \\
\hline $\begin{array}{l}\text { Teste } \mathrm{F} \\
\mathrm{F} \text { Test }(\text { Fat } \mathrm{x} \text { T) }\end{array}$ & $0,47 \mathrm{~ns}$ & $14,62 * *$ & $5,72^{*}$ & $5,60 *$ & $18,55^{* * *}$ & $6,38 *$ \\
\hline $\mathrm{CV}(\%)$ & 27,28 & 42,96 & 14,35 & 26,53 & 33,20 & 23,46 \\
\hline
\end{tabular}

** Médias seguidas por letras distintas diferem entre si pelo Teste de Tukey em nível de $1 \%$ de probabilidade.

** Averages followed by different letter differ themselves by the Tukey test at $1 \%$.

* Médias seguidas por letras distintas diferem entre si pelo Teste de Tukey em nível de $5 \%$ de probabilidade.

* Averages followed by different letter differ themselves by the Tukey test at $5 \%$.

${ }^{\text {ns }}$ Não significativo.

${ }^{\mathrm{ns}}$ Not significant. 
Tabela 5. Qualidade comercial de plantas de Aechmea fasciata (Lindley) Baker submetida a duas fontes potássicas em três freqüências de adubação potássica foliar.

Table 5. Quality of plants of Aechmea fasciata (Lindley) Baker subjected to two potash sources of in three frequencies of foliar fertilization.

\begin{tabular}{|c|c|}
\hline $\begin{array}{l}\text { Tratamentos } \\
\text { Treatments }\end{array}$ & $\begin{array}{l}\text { Qualidade Comercial } \\
\text { Quality }\end{array}$ \\
\hline Fonte & \\
\hline Source (Fo) & \\
\hline Cloreto de potássio & $1,26 \mathrm{~b}$ \\
\hline Potassium chloride & \\
\hline Sulfato de potássio & $1,48 \mathrm{a}$ \\
\hline Potassium sulfate & \\
\hline Teste F & $4,76^{* *}$ \\
\hline F Test & \\
\hline DMS (5\%) & 0,21 \\
\hline $\begin{array}{l}\text { Frequiência } \\
\text { Frequencies }(\mathrm{Fr})\end{array}$ & \\
\hline $\begin{array}{l}\text { Semanal } \\
\text { Weekly }\end{array}$ & $1,40 \mathrm{a}$ \\
\hline $\begin{array}{l}\text { Quinzenal } \\
\text { Fortnightly }\end{array}$ & $1,39 \mathrm{a}$ \\
\hline $\begin{array}{l}\text { Mensal } \\
\text { Monthly }\end{array}$ & $1,33 \mathrm{a}$ \\
\hline $\begin{array}{l}\text { Teste F } \\
\text { F Test }\end{array}$ & $0,28 \mathrm{~ns}$ \\
\hline DMS (5\%) & 0,32 \\
\hline $\begin{array}{l}\text { Teste F } \\
\mathrm{F} \text { Test }(\mathrm{Fo} \times \mathrm{Fr}) \\
\end{array}$ & $0,37 \mathrm{~ns}$ \\
\hline $\begin{array}{l}\text { Fatorial } \\
\text { Factorial (Fat) }\end{array}$ & $1,37 \mathrm{a}$ \\
\hline $\begin{array}{l}\text { Testemunha } \\
\text { Control }(\mathrm{T}) \\
\end{array}$ & $1,22 \mathrm{a}$ \\
\hline $\begin{array}{l}\text { Teste F } \\
\text { F Test (Eat x T) }\end{array}$ & $1,25 \mathrm{~ns}$ \\
\hline $\mathrm{CV}(\%)$ & 16,00 \\
\hline
\end{tabular}

** Médias seguidas por letras distintas diferem entre si pelo Teste de Tukey em nível de $1 \%$ de probabilidade.

** Averages followed by different letter differ themselves by the Tukey test at $1 \%$.

${ }^{\text {ns }}$ Não significativo.

${ }^{n s}$ Not significant. 